\title{
Regional differences and determinants of self-rated health in a lower middle income rural Society of China
}

\author{
Lidan Wang ${ }^{1 *}$, Weizhen Dong ${ }^{2}$, Yunqing $\mathrm{Ou}^{3}$, Shuting Chen ${ }^{4}$, Jingjing Chen ${ }^{5}$ and Qicheng Jiang ${ }^{6 *}$
}

\begin{abstract}
Objective: Self-rated health represents a reliable and important health measure related to general health and quality of life. This study aimed to identify the differences of health states of rural residents in a lower middle income setting in China and its associated factors.

Methods: A descriptive study of a stratified random sample of 3870 individuals was conducted in rural Anhui during 2015. We investigated the influence of five independent variables: individual demographic characteristics, family factors, social capital traits, physical health conditions and healthy lifestyle habits of participants who selfrelated their health as good. A chi-square test and ordinal logistic regression analyses were used to identify the relationship of these variables and self-rated health.
\end{abstract}

Results: The study found that respondents who negatively rated their health often were female, elderly, poor, lived alone, had low levels of education, inadequate social support, poor physical health, used healthcare services and lived in the lower economic regions. We found no significant correlations between self-rated health and employment, marital status, medical insurance, or exercise frequency. Surprisingly, smoking and drinking also seemed to be unrelated to poor self-reported health.

Conclusion: Health differences based on region were apparent in rural China. We highlighted the possible impacts of income, age, physical health, education, advanced age, and social support on health. The results from this study could inform the delivery of appropriate health and social healthcare interventions to promote rural residents' health and quality of life.

Keywords: Social determinants, Health status, Regional differences, Rural China

\section{Introduction}

Self-rated health (SRH) is widely known as a general perception of individual health status [1, 2], and a key indicator to measure health in population-based studies [3]. $\mathrm{SRH}$ has been approved by organizations such as the World Health Organization [4], because it provides a simpler [5], less expensive [6], more precise, and more objective measure of health compared to clinical evaluations [7]. Furthermore, the validity of SRH measure of self-report health has been firmly established in population studies.

\footnotetext{
*Correspondence: wanglidan@ahmu.edu.cn; jiangqicheng@ahmu.edu.cn ${ }^{1}$ School of Health Management, Anhui Medical University, No.81, Mei Shan Road, Hefei 230032, Anhui, China

${ }^{6}$ School of Public Health, Anhui Medical University, No.81, Mei Shan Road, Hefei 230032, Anhui, China

Full list of author information is available at the end of the article
}

The profound understanding of predictors of good SRH for persons in the general population has increased considerably in recent years. Initially an exploration of SRH began with personal demographic characteristics (e.g. age, gender, marital status, education, income) [8, 9], individual healthy lifestyle habits (e.g. smoking, poor nutrition, lack of exercise, drinking, awareness of dietary guidelines) [2, 10], and the state of physical and mental health (e.g. functional capacity, family history of hereditary disease, depression, anxiety, work stress) $[11,12]$. Investigators have broadened the field of study to include broad-social concerns (social capita, social support, neighbor quality) [13-15] and factors related to living conditions (e.g. housing conditions, material conditions, level of crime, regional

(c) The Author(s). 2018 Open Access This article is distributed under the terms of the Creative Commons Attribution 4.0 International License (http://creativecommons.org/licenses/by/4.0/), which permits unrestricted use, distribution, and reproduction in any medium, provided you give appropriate credit to the original author(s) and the source, provide a link to the Creative Commons license, and indicate if changes were made. The Creative Commons Public Domain Dedication waiver (http://creativecommons.org/publicdomain/zero/1.0/) applies to the data made available in this article, unless otherwise stated. 
differences, economic crisis, psychosocial conditions) $[10$, $15,16]$.

In general, domestic studies have focused on the elderly or urban residents [17]. However, the use of SRH measures of the health of rural residents has lagged, presumably because of the assumption that the characteristics of socioeconomic, healthy lifestyle habits, physical health and utilization of healthcare services, prove widely divergent in the large area that rural China encompasses. Interestingly, disparities in heath statuses among different regions in China have elicited a growing concern for the health challenges of rural populations. How do rural residents view their own health? What shapes the regional discrepancies among rural residents' SRH levels? To address these questions demands an examination of the factors associated with SRH. A better understanding of the impact that social factors have on rural residents' SRH would permit the development of improved intervention strategies to assure enhanced quality of health in later life.

The present study was conducted with rural residents of Anhui Province to identify health conditions among the population as well as the regional disparities that exist. Factors that influenced rural residents' SRH were examined to determine if they were different from those in other regions and to provide data that could contribute to the improvement of health conditions in rural area and lower middle income societies.

\section{Methods}

\section{Ethics statement}

The study was approved by the Anhui Medical University Research Ethics Committee. Each participant received an explanation of the significance of the study and a form that outlined the protection of personal information from trained data collectors. All participants provided written informed consent.

\section{Data collection}

Anhui province is located in the east of China. The province boasted 61.436 million permanent residents in 2015 (ranking 8th among 34). The Gross Domestic Product (GDP) of Anhui was 5808 dollars per capita in 2015, ranking 25th among 34. The Percentage of healthcare to consumer expenditures in rural areas was $8.99 \%$ [18]. The study included Anhui rural residents over the age of 15 years old as research subjects. Under a multi-stage stratified random sampling method, the survey randomly selected 3 of the 16 municipalities, representing three geographical areas (southern, central and northern regions). In each 3 regions, 2 counties were selected by economic level (wealthier and poorer). Three villages were randomly selected from each county. A total of 18 villages in 3 regions were selected. All the permanent and available residents from farming households were invited to participate in the survey. In this study, "permanent residents" were defined as those who spent more than 6 months out of the year at the registered place of residence. From June to August 2015, the survey was conducted in the subjects' homes. The questions covered demographic and socio-economic information on individuals and households, socio-economic status, physical health, and healthy lifestyle habits.

A total of 3870 valid questionnaires were collected from the 3 regions. Additional information on the geography and economic profiles of the regions was collected from local statistics bureaus (Table 1).

\section{Definition of key study variables Dependent variable}

In the study, SRH status was assessed using the single-item question "What would you say that your overall physician heath is?" Participants were asked to complete the sentence with a number on a scale of 0 (poor) to 100 (excellent). Additionally, participants were asked to provide a score that captures their health on that day they completed the survey. The scores were divided into 4 quartiles from lowest (scores of less than 60.00 ) to highest (scores higher than 90.00).

\section{Independent variables}

The independent variables included were as follows: individual demography characteristics, family factors, social capital traits, physical health, and healthy lifestyle habits. Individual demography characteristics included gender, age, education and employment status. Family factors included marital status, annual household income per capita, and family composition. Annual household income per capita was divided into 4 quartiles from lowest to highest. Indicators of social capital traits included medical insurance and social support. In urban China, there were two main forms of medical insurance during the time of the study, medical insurance for urban employees and medical insurance for urban residents respectively. In

Table 1 Socioeconomic characteristics of sampled regions (2015)

\begin{tabular}{lllll}
\hline Variable & $\begin{array}{l}\text { Southern } \\
\text { region }\end{array}$ & $\begin{array}{l}\text { Central } \\
\text { region }\end{array}$ & $\begin{array}{l}\text { Northern } \\
\text { region }\end{array}$ & $\begin{array}{l}\text { Total } \\
\text { Anhui }\end{array}$ \\
\hline Population/square kilometers & 459 & 420 & 652 & 438 \\
Per capita GDP $(\$)$ & 13,001 & 2968 & 1769 & 5808 \\
$\begin{array}{l}\text { Per capita disposable income } \\
\text { of rural household(\$) }\end{array}$ & 2835 & 2298 & 1482 & 1738 \\
$\begin{array}{l}\text { Numbers of medical practitioners } \\
\text { /1000 population }\end{array}$ & 2.07 & 2.28 & 1.07 & 1.55 \\
$\begin{array}{l}\text { Utilization rate of city hospital } \\
\text { beds (\%) }\end{array}$ & 82.44 & 86.36 & 86.66 & 84.97 \\
$\begin{array}{l}\text { Utilization rate of township } \\
\text { hospital beds (\%) }\end{array}$ & 26.65 & 51.13 & 80.70 & 60.64 \\
\hline
\end{tabular}


addition, the New Rural Cooperative Medical System (NRCM) was introduced in 2003 and extended to almost all rural residents by 2010. The Social Support Rating Scale (SSRS) was used to measure social support, including the three dimensions of objective support, subjective support, and utilization of social resources. The scores were grouped from lowest to highest.

Physical health conditions included clinic visits (in the past two weeks), hospitalization (during the past year) and the presence of common chronic disease (such as hypertension disease, diabetes disease, cardiovascular and cerebrovascular diseases) diagnosed by doctor. Healthy lifestyle habits included outdoor exercise, as well as the absence of smoking or drinking. Residence was divided geographically into southern, central, and northern regions of Anhui province. Definitions of the variables appears in Table 2 .

\section{Active exercise}

Outdoor exercise was assessed with the following item: "Including all types of outdoor exercise, how many times during one week did you exercise outdoors for more than 30 minutes in the last 12 months, excluding everyday activities and working in the field?" Those who reported exercise on one or more occasions were categorized as "Yes;" all other participant response were labeled "No."

\section{Smoking status}

Smoking status was assessed with the following item: What is your history of cigarette smoking? Possible responses were: (1) I have never smoked; (2) I only smoked on one or two occasions; (3) I smoked regularly (at least once per day), but have quit; (4) I smoked, but not every day; and (5) I smoked every day. Participants selecting responses 1, 2 or 3 were labelled "not a smoker," participants selecting responses 4 or 5 were defined "Smoker."

\section{Drinking status}

Level of drinking was determined by the following question: How many times in any given week did you drink in the last year? Possible responses were: (1) I have never drunk; (2) I used to drink but quit at least 6 months ago; (3) I only drank on one or two occasions; (4) I drank less than 3 times a week, and (5) I drank at least 3 times a week. Participants who chose responses 1,2 or 3 were defined as "tot a drinker", participants who chose responses 4 were defined as " $<3$ times/week," and respondents who selected responses 5 were defined as " $\geq 3$ times/week."

\section{Statistical analysis}

Data analysis was conducted using SPSS 23.0. Differential testing was conducted using a chi-square test. A series of ordinal logistic regression models were performed to determine associations between $\mathrm{SRH}$ and the independent variables. A value of $P<0.05$ was considered to be significant.

\section{Results}

Characteristics of the sampled regions and participants

The central region was close to the provincial capital, and the per capita. The GDP per capita was \$2986 in 2015. The southern region showed the highest economic level (per capita GDP, \$13001) and the highest disposable income ( $\$ 2835$ per capita). Residents of the northern plain lived closer to each other (652 persons per $\mathrm{km}^{2}$ ), the lowest economic level and the fewest number of medical practitioners (1.07/1000 residents). However, the utilization rate of city and township hospital beds were highest in the northern region $(86.66 \%$ and $80.70 \%$, respectively). The disparity of utilization of township hospitals beds among the 3 regions was larger than that of city hospitals (Table 1 ).

As shown in Table 2, the demographic composition of the 3 regions indicated no statistically significant difference in terms of marital status $(P>0.05)$, but all of the demographic social traits were statistically distinct. There were more residents who were female (63.24\%), over 65 years of age (29.50\%), without education (52.02\%), subsistence farmers (83.49\%), and elderly living alone $(50.74 \%)$ in the northern region than elsewhere. Most of the sampled households used by NRCM coverage, especially in the northern region (98.81\%). Northern residents demonstrated the highest social support (47.98\%), chronic illnesses $(57.90 \%)$, injury or illness within the past two weeks (60.00\%), hospitalizations within the past year $(77.50 \%)$, outdoor exercise $(25.46 \%)$, and abstinence from alcohol (86.21\%). However, few northern residents smoked (16.39\%).

\section{Individual and family traits and health}

In general, there were statistically significant differences with regard to the association between SRH and demographic traits, with the exception of gender, medical insurance and active exercise (Table 3). The SRH levels of male and female did not prove significantly different between the central and northern regions.

Among all participants, the best levels of SRH among respondents aged 15 to 44 years were among participants who had higher levels of education, and were not subsistence farmers. Those who were married had higher SRH. Greater income also was associated with higher SRH. A total of $65.09 \%$ of the residents in the poorest income quartile in the northern region reported the poorest SRH. Elderly who lived alone reported the poorest.

\section{Strong social support positively impact good health}

Among people in the northern region, those without medical insurance reported the poorest SRH (46.23\%). 
Table 2 Descriptive characteristics of participants in different districts (\%)

\begin{tabular}{|c|c|c|c|c|c|}
\hline Variable & & $\begin{array}{l}\text { Southern region } \\
(n=1245)\end{array}$ & Central region $(n=1537)$ & $\begin{array}{l}\text { Northern region } \\
(n=1088)\end{array}$ & $\begin{array}{l}\text { Total Anhui } \\
(n=3870)\end{array}$ \\
\hline \multirow[t]{2}{*}{ Gender $^{* *}$} & Male & 42.62 & 40.45 & 36.76 & 40.27 \\
\hline & Female & 57.38 & 59.55 & 63.24 & 59.73 \\
\hline \multirow[t]{4}{*}{ Age $(y)^{* *}$} & $15 \sim$ & 25.31 & 28.11 & 19.58 & 24.60 \\
\hline & $45 \sim$ & 29.02 & 28.27 & 26.29 & 28.01 \\
\hline & $55 \sim$ & 22.58 & 21.29 & 24.63 & 22.74 \\
\hline & $65 \sim$ & 23.10 & 22.33 & 29.50 & 24.65 \\
\hline \multirow[t]{3}{*}{ Education $^{* *}$} & No education & 42.64 & 38.63 & 52.02 & 43.99 \\
\hline & Primary school & 26.04 & 27.95 & 25.55 & 26.52 \\
\hline & Middle school or higher & 31.32 & 33.41 & 22.43 & 29.49 \\
\hline \multirow[t]{2}{*}{ Employment status $^{* *}$} & Subsistence farmers & 68.50 & 57.19 & 83.49 & 69.13 \\
\hline & Others & 31.50 & 42.81 & 16.51 & 30.87 \\
\hline \multirow[t]{2}{*}{ Marital statue } & Married & 88.29 & 85.70 & 85.37 & 86.64 \\
\hline & Others & 11.71 & 14.30 & 14.63 & 13.36 \\
\hline \multirow[t]{4}{*}{ Income* } & Q1 ( 25\%) & 24.06 & 24.75 & 24.36 & 24.37 \\
\hline & Q2 & 24.96 & 25.22 & 24.74 & 24.99 \\
\hline & Q3 & 27.24 & 24.34 & 23.76 & 25.38 \\
\hline & Q4(75\% ) & 23.73 & 25.69 & 27.15 & 25.26 \\
\hline \multirow[t]{5}{*}{ Household composition $^{* *}$} & Parents and children & 26.22 & 30.44 & 19.85 & 25.79 \\
\hline & Three generations & 27.33 & 19.52 & 15.17 & 21.40 \\
\hline & Elderly and children & 8.46 & 5.78 & 13.97 & 9.15 \\
\hline & Only elderly & 37.54 & 43.78 & 50.74 & 43.26 \\
\hline & Others & 0.46 & 0.48 & 0.28 & 0.41 \\
\hline \multirow[t]{3}{*}{ Medical insurance } & NRCMs & 96.16 & 88.51 & 98.81 & 94.44 \\
\hline & Other medical insurances & 2.86 & 7.87 & 0.74 & 3.88 \\
\hline & No medical insurance & 0.98 & 3.61 & 0.46 & 1.68 \\
\hline \multirow[t]{4}{*}{ Social support ${ }^{* *}$} & Q1 ( 25\%) & 25.70 & 24.74 & 47.98 & 31.65 \\
\hline & Q2 & 21.21 & 21.61 & 21.23 & 21.34 \\
\hline & Q3 & 25.11 & 27.39 & 15.90 & 23.26 \\
\hline & Q4(75\% ) & 27.98 & 26.27 & 14.89 & 23.75 \\
\hline \multirow[t]{2}{*}{ Chronic disease $^{* *}$} & No & 48.86 & 54.49 & 42.10 & 48.77 \\
\hline & Yes & 51.14 & 45.51 & 57.90 & 51.23 \\
\hline \multirow[t]{2}{*}{ Clinic visit $^{* *}$} & No & 61.99 & 57.98 & 40.00 & 54.54 \\
\hline & Yes & 38.01 & 42.02 & 60.00 & 45.46 \\
\hline \multirow[t]{2}{*}{ Hospitalization } & No & 11.05 & 11.66 & 22.50 & 14.46 \\
\hline & Yes & 88.95 & 88.34 & 77.50 & 85.54 \\
\hline \multirow[t]{2}{*}{ Active exercise ${ }^{* *}$} & No & 80.29 & 68.40 & 73.40 & 74.52 \\
\hline & Yes & 19.71 & 31.60 & 26.60 & 25.46 \\
\hline \multirow[t]{2}{*}{ Smoke } & No & 78.09 & 77.98 & 83.61 & 79.60 \\
\hline & Yes & 21.91 & 22.02 & 16.39 & 20.40 \\
\hline \multirow[t]{3}{*}{ Drink $^{* *}$} & No & 76.58 & 77.51 & 86.21 & 79.59 \\
\hline & $<3$ times/week & 8.56 & 7.31 & 5.15 & 7.24 \\
\hline & $\geq 3$ times/week & 14.77 & 15.18 & 8.64 & 13.18 \\
\hline
\end{tabular}

${ }^{a}$ Other medical insurance: basic medical insurance for urban and rural residents, commercial health insurance

${ }^{b}$ Below the median score

'Equal to or higher than the median score

* Significant difference among respondents from 3 regions at $P<0.05$ level

${ }^{* *}$ Significant difference among respondents from 3 regions respondents at $P<0.01$ level 
Table 3 Percentage of self-rated health among different groups (\%)

\begin{tabular}{|c|c|c|c|c|c|c|c|c|c|c|c|c|c|}
\hline \multirow[t]{2}{*}{ Characteristic } & & \multicolumn{4}{|c|}{ Southern region } & \multicolumn{4}{|c|}{ Central region } & \multicolumn{4}{|c|}{ Northern region } \\
\hline & & Poorest & Poor & Good & Best & Poorest & Poor & Good & Best & Poorest & Poor & Good & Best \\
\hline \multirow[t]{2}{*}{ Gender } & Male & $21.27^{* *}$ & 20.48 & 26.84 & 31.41 & 25.19 & 20.00 & 25.19 & 29.62 & 46.25 & 20.75 & 16.50 & 16.50 \\
\hline & Female & 27.09 & 22.37 & 27.76 & 22.78 & 26.08 & 22.11 & 25.06 & 26.76 & 48.98 & 21.51 & 15.55 & 13.95 \\
\hline \multirow[t]{4}{*}{ Age(y) } & $15 \sim$ & $10.86^{* *}$ & 16.00 & 31.14 & 42.00 & $10.54^{* *}$ & 16.97 & 27.76 & 44.73 & $25.35^{* *}$ & 16.90 & 22.54 & 35.21 \\
\hline & $45 \sim$ & 18.18 & 23.58 & 28.13 & 30.11 & 21.75 & 25.56 & 25.34 & 27.35 & 42.66 & 21.33 & 19.58 & 16.43 \\
\hline & $55 \sim$ & 35.85 & 24.53 & 23.40 & 16.23 & 33.14 & 18.44 & 25.65 & 22.77 & 51.12 & 24.25 & 14.55 & 10.07 \\
\hline & $65 \sim$ & 39.93 & 23.38 & 25.54 & 11.15 & 40.00 & 23.10 & 21.41 & 15.49 & 65.11 & 21.50 & 9.35 & 4.05 \\
\hline \multirow[t]{3}{*}{ Education } & No education & $35.34^{* *}$ & 24.74 & 26.40 & 13.51 & $36.64^{* *}$ & 21.37 & 23.51 & 18.47 & $57.07^{* *}$ & 21.55 & 12.90 & 8.48 \\
\hline & Primary school & 28.45 & 22.99 & 25.86 & 22.70 & 22.50 & 24.25 & 24.50 & 28.75 & 44.24 & 22.30 & 16.55 & 16.91 \\
\hline & Middle school or higher & 9.38 & 16.83 & 29.81 & 43.99 & 13.51 & 18.50 & 27.65 & 40.33 & 31.15 & 19.26 & 22.13 & 27.46 \\
\hline \multirow[t]{2}{*}{ Employment status } & Subsistence farmers & $28.87^{* *}$ & 23.38 & 27.32 & 20.42 & $29.53^{* *}$ & 22.79 & 24.41 & 23.27 & $47.91^{* *}$ & 22.69 & 16.19 & 13.22 \\
\hline & Others & 19.25 & 19.25 & 27.48 & 34.02 & 17.36 & 17.77 & 26.65 & 38.22 & 48.33 & 13.89 & 14.44 & 23.33 \\
\hline \multirow[t]{2}{*}{ Marital status } & Married & $22.77^{* *}$ & 21.65 & 27.84 & 27.74 & $24.39^{* *}$ & 21.08 & 25.50 & 29.03 & $46.23^{* *}$ & 21.34 & 16.27 & 16.16 \\
\hline & Others & 36.52 & 21.35 & 24.72 & 17.42 & 35.56 & 22.22 & 22.22 & 20.00 & 57.86 & 20.75 & 13.84 & 7.55 \\
\hline \multirow[t]{4}{*}{ Income } & Q1 ( 25\%) & $45.66^{* *}$ & 21.86 & 21.22 & 11.25 & $40.38^{* *}$ & 22.22 & 20.05 & 17.34 & $65.09^{* *}$ & 18.18 & 12.00 & 4.73 \\
\hline & Q2 & 23.30 & 25.89 & 26.86 & 23.95 & 28.53 & 22.01 & 24.73 & 24.73 & 49.65 & 25.18 & 13.83 & 11.35 \\
\hline & Q3 & 16.61 & 20.27 & 30.56 & 32.56 & 19.47 & 20.43 & 25.96 & 34.13 & 42.52 & 21.65 & 17.32 & 18.50 \\
\hline & Q4(75\% ) & 12.94 & 19.09 & 30.74 & 37.22 & 16.09 & 19.84 & 29.22 & 34.85 & 34.19 & 19.85 & 20.59 & 25.37 \\
\hline \multirow[t]{5}{*}{ Household composition } & Parents and children & $17.15^{* *}$ & 20.84 & 25.07 & 36.94 & $17.37^{* *}$ & 21.84 & 23.33 & 37.47 & $35.19^{* *}$ & 17.59 & 18.52 & 28.70 \\
\hline & Three generations & 20.16 & 19.75 & 28.40 & 31.69 & 21.67 & 20.00 & 29.05 & 29.29 & 36.97 & 20.61 & 18.79 & 23.64 \\
\hline & Elderly and children & 25.00 & 20.83 & 31.94 & 22.22 & 30.00 & 17.69 & 20.00 & 32.31 & 44.08 & 27.63 & 15.13 & 13.16 \\
\hline & Only elderly & 31.93 & 23.30 & 27.89 & 16.88 & 33.80 & 22.01 & 24.78 & 19.41 & 57.07 & 21.20 & 14.31 & 7.43 \\
\hline & Others & 33.33 & 0.00 & 33.33 & 33.33 & 0.00 & 57.14 & 14.29 & 28.57 & 100.00 & 0.00 & 0.00 & 0.00 \\
\hline \multirow[t]{3}{*}{ Medical insurance } & NRCMs & $24.68^{* *}$ & 22.87 & 27.22 & 25.23 & 26.05 & 20.84 & 25.03 & 28.08 & $48.00^{* *}$ & 21.40 & 15.91 & 14.70 \\
\hline & Other medical insurances & 20.41 & 14.29 & 26.53 & 38.78 & 18.18 & 29.55 & 25.00 & 27.27 & 37.50 & 0.00 & 12.50 & 50.00 \\
\hline & No medical insurance & 35.56 & 6.67 & 33.33 & 24.44 & 13.33 & 33.33 & 33.33 & 20.00 & 60.00 & 20.00 & 20.00 & 0.00 \\
\hline \multirow[t]{4}{*}{ Social support } & Q1 ( 25\%) & $38.06^{* *}$ & 21.67 & 24.44 & 15.83 & $35.42^{* *}$ & 21.30 & 21.30 & 21.99 & $61.09^{* *}$ & 19.94 & 10.93 & 8.04 \\
\hline & Q2 & 26.86 & 24.03 & 26.50 & 22.61 & 26.97 & 21.72 & 23.63 & 27.68 & 48.03 & 23.03 & 16.12 & 12.83 \\
\hline & Q3 & 18.55 & 22.01 & 29.56 & 29.87 & 20.96 & 20.40 & 25.21 & 33.43 & 42.11 & 26.32 & 16.12 & 15.46 \\
\hline & Q4(75\% ) & 12.68 & 18.66 & 29.58 & 39.08 & 16.52 & 21.32 & 31.83 & 30.33 & 34.32 & 11.24 & 24.26 & 30.18 \\
\hline \multirow[t]{2}{*}{ Chronic disease } & No & $11.95^{* *}$ & 17.99 & 31.12 & 38.94 & $11.58^{* *}$ & 16.78 & 27.96 & 43.68 & $25.11^{* *}$ & 22.49 & 24.24 & 28.17 \\
\hline & Yes & 40.04 & 25.93 & 22.93 & 11.11 & 39.19 & 25.45 & 22.39 & 12.98 & 64.60 & 20.32 & 9.84 & 5.24 \\
\hline \multirow[t]{2}{*}{ Clinic visit } & No & $13.29^{* *}$ & 18.88 & 30.91 & 36.92 & $15.07^{* *}$ & 18.65 & 28.13 & 38.15 & $24.19^{* *}$ & 22.56 & 24.42 & 28.84 \\
\hline & Yes & 40.46 & 25.43 & 22.93 & 11.18 & 42.96 & 25.60 & 19.93 & 11.51 & 63.88 & 20.16 & 10.39 & 5.58 \\
\hline \multirow[t]{2}{*}{ Hospitalization } & No & $20.55^{* *}$ & 22.11 & 28.99 & 28.35 & $22.63^{* *}$ & 21.09 & 26.01 & 30.27 & $42.89^{* *}$ & 21.98 & 18.40 & 16.73 \\
\hline & Yes & 56.25 & 18.06 & 16.67 & 9.03 & 50.30 & 22.49 & 17.16 & 10.06 & 65.84 & 18.52 & 7.41 & 8.23 \\
\hline \multirow[t]{2}{*}{ Active exercise } & No & 25.30 & 21.38 & 28.38 & 24.94 & $27.73^{* *}$ & 21.04 & 24.47 & 26.75 & 46.59 & 21.34 & 16.92 & 15.15 \\
\hline & Yes & 23.39 & 22.37 & 25.96 & 28.28 & 17.28 & 21.93 & 27.24 & 33.55 & 51.92 & 20.91 & 13.24 & 13.94 \\
\hline \multirow[t]{2}{*}{ Smoke } & No & $26.27^{* *}$ & 22.95 & 27.00 & 23.78 & $27.14^{* *}$ & 21.78 & 24.54 & 26.55 & $50.17^{* *}$ & 21.82 & 15.06 & 12.96 \\
\hline & Yes & 19.12 & 16.91 & 29.41 & 34.56 & 20.30 & 19.70 & 26.57 & 33.43 & 37.29 & 18.08 & 20.34 & 24.29 \\
\hline \multirow[t]{3}{*}{ Drink } & No & $27.25^{* *}$ & 22.38 & 26.74 & 23.63 & $29.14^{* *}$ & 21.07 & 24.13 & 25.66 & $50.43^{* *}$ & 22.49 & 14.39 & 12.69 \\
\hline & $<3$ times/week & 16.48 & 20.88 & 19.78 & 42.86 & 8.27 & 20.30 & 27.07 & 44.36 & 35.71 & 10.71 & 28.57 & 25.00 \\
\hline & $\geq 3$ times/week & 15.87 & 17.99 & 34.39 & 31.75 & 18.06 & 22.47 & 29.07 & 30.40 & 30.85 & 14.89 & 23.40 & 30.85 \\
\hline \multicolumn{2}{|l|}{ Region $^{* *}$} & 24.74 & 21.61 & 27.39 & 26.27 & 25.70 & 21.21 & 25.11 & 27.98 & 47.98 & 21.23 & 15.90 & 14.89 \\
\hline
\end{tabular}


However, medical insurance varied in the different regions. The residents who were covered by NRCMs exhibited the poorest SRH in the southern region (24.68\%) and northern region $(48.00 \%)$. However, the SRH of respondent with different medical insurance plans in the central region showed no statistical difference among them. Regardless of the region where the respondents resided, the entire sample with better social support had higher SRH scores. However, the trend was not consistent across the three regions; the highest SRH were found in quartile 4 in the southern and northern regions, and in quartile 3 in the central region.

\section{Better physical health consistent with better SRH}

The participants with chronic illness, illness in the past two weeks, or a hospitalization within the past year, had poorer SRH than other participants. More than half reported the poorest SRH among respondents with chronic disease, had made a clinic visit and had been hospitalized in the northern region $(64.60 \%, 63.88 \$$ and $65.84 \%$, respectively). However, the highest rate of poor SRH was among respondents with poor physical health in the southern and central regions.

\section{Health lifestyles positively impact good health}

In the central region, the population who actively exercised had higher SRH than other participants (33.55\%). In the southern and northern regions, the percentage of participants who exercised showed no statistical difference compared to the other respondents. However, most respondent who smoked or drank reported better SRH. These traits were more clearly represented in the southern and central regions; in the northern region, the highest rate of poor SRH was found among responders who did not smoke or drank.

Overall, the SRH among northern respondents was lower than that of southern and central regionals $(p<0.05)$, and nearly half of them $(47.98 \%)$ reported the poorest SRH.

\section{Determinants of SRH in rural regions}

The odds ratios of SRH in a series of models are presented in Table 4. In the first, districts were included, followed by a regression analysis of individual demographic characteristics, family factors, physical health and healthy lifestyle habits.

Model 1 served to demonstrate that the place of residence was a significant determinant of poor SRH. The respondents who lived in the northern region were more likely to have poor SRH.

Model 2 indicated that gender, age and education were all associated with SRH. Female respondents were 1.184 times more likely than males to have poor SRH. The likelihood of poor SRH levels increased with age. Education demonstrated a protective effect; participants with higher level of education were less likely to have poor SRH.

As shown in the Model 3, the residents with higher incomes were less likely to have poor SRH than those who were impoverished. Participants in the wealthiest income quartile reported low SRH less than (0.447 times) those in the poorest quartile. However, marriage status, family composition and employment demonstrated no significant impact on SRH levels.

In Model 4, social support was included. The respondents who reported strong social support were 0.608 times more likely to have a poor SRH. Medical insurance was not included in the model, although the family composition was. The elderly living alone were more likely (1.118 times) to report poor SRH than the others.

Model 5 included the variables related to physical health: chronic diseases, illnesses, clinic visits and hospitalizations. These physical health variables were all significantly associated with SRH.

All of the covariates were analyzed in Model 6. The smoking population showed a lower likelihood (0.745 times) to report poor SRH. Furthermore, the people who drank more than twice a week were 0.627 times less likely to have poor SRH than people who did not drink. Respondents who actively exercised did not show lower SRH levels. Furthermore, gender was proved irrelevant in this model.

Logistic regression analysis revealed that region, age, education, household income, social support, physical health, healthy lifestyle habits were all associated with SRH.

\section{Discussion}

In this study we investigated the association between five category factors and SRH, including individual demographic characteristics, family factors, social capital traits, physical health, and healthy lifestyle habits, using the data form a lower-middle-income rural society in China.

\section{Comparison to previous studies}

The study's findings factors of importance among regions with wide disparities, even within the same province. More importantly, the results suggested associations between SRH and a variety of factors, women, elderly, respondents with lower level of education, who lived alone, lower-income individuals, people with low levels of social support, and those with poor physical health all fared worse on SRH [10, 14, 19-21]. Additionally, smoking and consuming small amounts of alcohol were associated with good SRH.

\section{Region condition and residents' SRH}

Region of residence was found to affect SRH scores in all of the models. Previous studies have demonstrated that place of residence proved relevant to SRH scores $[8,22]$. The findings form this study were consistent with 
Table 4 Ordinal logistic regression of respondents' SRH (Exp (B))

\begin{tabular}{|c|c|c|c|c|c|c|}
\hline Variable & Model $1^{\text {a }}$ & Model $2^{b}$ & Model $3^{c}$ & Model $4^{d}$ & Model $5^{\mathrm{e}}$ & Model $6^{f}$ \\
\hline \multicolumn{7}{|l|}{ SRH(ref: Poorest) } \\
\hline Poor & $2.873^{* *}$ & $4.967^{* *}$ & $3.038^{* *}$ & $2.433^{* *}$ & $4.827^{* *}$ & $3.447^{* *}$ \\
\hline Good & $1.331^{*}$ & $1.776^{* *}$ & 1.061 & 0.844 & $1.479^{*}$ & 1.045 \\
\hline Best & $0.384^{* *}$ & $0.536^{* *}$ & $0.315^{* *}$ & $0.249^{* *}$ & $0.387^{* *}$ & $0.270^{* * *}$ \\
\hline \multicolumn{7}{|l|}{ Region (ref: Southern) } \\
\hline Central & 0.994 & 0.948 & 0.999 & 0.993 & 0.962 & 0.957 \\
\hline Northern & $2.557^{* *}$ & $2.139^{* *}$ & $2.276^{* *}$ & $2.278^{* *}$ & $1.992^{* *}$ & $1.932^{* *}$ \\
\hline \multicolumn{7}{|l|}{ Gender (ref: Male) } \\
\hline Female & & $1.184^{*}$ & $1.236^{* *}$ & $1.255^{* *}$ & $1.217^{*}$ & 0.879 \\
\hline \multicolumn{7}{|l|}{ Age (y) (ref: 15 ) } \\
\hline $45 \sim$ & & $1.825^{* *}$ & $1.765^{* * *}$ & $1.782^{* *}$ & $1.413^{* *}$ & $1.472^{* *}$ \\
\hline $55 \sim$ & & $2.663^{* *}$ & $2.190^{* * *}$ & $2.155^{* *}$ & $1.525^{* *}$ & $1.562^{* *}$ \\
\hline $65 \sim$ & & $3.899^{* *}$ & $2.655^{* * *}$ & $2.578^{* *}$ & $1.727^{* *}$ & $1.772^{* *}$ \\
\hline \multicolumn{7}{|l|}{ Education (ref: No education) } \\
\hline Primary school & & $0.776^{* *}$ & $0.811^{* *}$ & $0.836^{*}$ & 0.896 & 0.859 \\
\hline Middle school or higher & & $0.501^{* *}$ & $0.546^{* *}$ & $0.576^{* *}$ & $0.655^{* *}$ & $0.661^{* *}$ \\
\hline \multicolumn{7}{|l|}{ Income (ref: Q1) } \\
\hline Q2 & & & $0.613^{* *}$ & $0.647^{* *}$ & $0.696^{* *}$ & $0.706^{* *}$ \\
\hline Q3 & & & 0.497 & $0.507^{* *}$ & $0.555^{* *}$ & $0.554^{* *}$ \\
\hline Q4 & & & $0.447^{* *}$ & $0.475^{* *}$ & $0.498^{* *}$ & $0.499^{* *}$ \\
\hline \multicolumn{7}{|c|}{ Household composition (ref: Parents and children) } \\
\hline Three generations & & & & 0.868 & 0.874 & 0.871 \\
\hline Elderly and children & & & & 0.784 & 0.775 & 0.767 \\
\hline Only elderly & & & & $1.118^{*}$ & $0.995^{*}$ & $0.988^{*}$ \\
\hline Others & & & & 2.114 & 2.032 & 2.291 \\
\hline \multicolumn{7}{|l|}{ Social support (ref: Poorer) } \\
\hline Poor & & & & $0.792^{* *}$ & $0.833^{*}$ & $0.620^{* *}$ \\
\hline Good & & & & $0.701^{* *}$ & $0.730^{* *}$ & $0.735^{* *}$ \\
\hline Better & & & & $0.608^{* *}$ & $0.599^{* *}$ & $0.836^{*}$ \\
\hline \multicolumn{7}{|l|}{ Chronic disease (ref: No) } \\
\hline Yes & & & & & $2.303^{* *}$ & $2.235^{* *}$ \\
\hline \multicolumn{7}{|l|}{ Clinic visit (ref: No) } \\
\hline Yes & & & & & $1.794^{* *}$ & $1.807^{* *}$ \\
\hline \multicolumn{7}{|l|}{ Hospitalization (ref: No) } \\
\hline Yes & & & & & $2.220^{* *}$ & $2.126^{* *}$ \\
\hline \multicolumn{7}{|l|}{ Smoke (ref: No) } \\
\hline Yes & & & & & & $0.745^{* *}$ \\
\hline \multicolumn{7}{|l|}{ Drink (ref: No) } \\
\hline$<3$ times/week & & & & & & $0.685^{* *}$ \\
\hline$\geq 3$ times/week & & & & & & $0.627^{* *}$ \\
\hline Chi-square & 203.772 & 739.745 & 835.445 & 864.839 & 1374.133 & 1409.634 \\
\hline$d f$ & 2 & 9 & 17 & 22 & 25 & 29 \\
\hline Sig. & 0.000 & 0.000 & 0.000 & 0.000 & 0.000 & 0.000 \\
\hline
\end{tabular}

ref: reference group; ${ }^{*}: P<0.05 ;{ }^{* *}: P<0.01$

a Model 1 Single-factor analysis

${ }^{\mathrm{b}}$ Model 2 Adjusted for individual traits (age, gender, education, employment)

${ }^{c}$ Model 3 Adjusted for the covariates in Model 2 and household characteristics (marital status, income, household composition)

dModel 4 Adjusted for the covariates in Model 3 as well as social support and medical insurance

${ }^{\mathrm{e}}$ Model 5 All covariates in Model 4 and physical health (chronic illness, illness, hospitalization)

${ }^{f}$ Model 6 All covariates in Model 5 and healthy habits (exercise, smoking and drinking) 
those form previous studies, that suggested that household better economic conditions positively impacted SRH [15]. In this study, the northern region's lower economic levels and decreased access to medical resources affected the quality of health services provided that, in turn, affected its residents' reported health. Policymakers should pay attention to the northern residents' relatively poor subjective health scores. Economic and public policies that address inequities in the quality of health care services provided may improve residents' health [23].

This research demonstrated that marital status had no significant effect on SRH. Previous research also has shown that there were that no significant correlations between SRH and housing quality, or marital status [14]. The fact that the majority of the participants in this study were married may have contributed to this finding. High levels of social support corresponded to higher SRH scores. The measure of SRH permitted an individual to independently determine which factors contribute to their health. Rich social relationship networks could have contributed to positive perceptions about health, low levels of social support could be associated with low SRH $[10,24]$. Perceptions about one's own health could be enhanced through the creation of positive community environments and harmonious family atmospheres. The participants who experienced hypertension, diabetes, cancer or had been hospitalized were more likely to report poor health $[17,25]$. The perception of a person's overall health was affected by the appearance of chronic conditions or serious illnesses. Therefore, subjective perception also depended on objective health $[5,26]$.

\section{Medical insurance and SRH}

This study evidenced no differences in SRH among residents with different types of medical insurance. This may have been because residents in these regions enjoyed coverage primarily through the NRCMs, with less access to other types of insurance. Since 2009, Anhui Province has gradually implemented a merger between NRCMs and urban resident medical insurance. The new insurance model will be referred to as "urban and rural resident medical insurance." In some regions-particularly in the south-rural businesses have purchased private insurance or urban employee medical insurance for some part-time rural resident workers. The fact that some workers enjoyed double coverage could partially explain why medical insurance did not seem to impact SRH scores. This also demonstrated that access to additional types of insurance coverage (such as commercial medical insurance) and implementation of a more comprehensive medical insurance package could serve to improve rural residents' perception of their health [22].

\section{Healthy lifestyle habits and SRH}

The study sustained findings form previous research that better SRH was reported among people who smoked cigarettes and consumed alcohol [27]. However, this finding contradicted an earlier study that associated smoking and drinking with lower SRH scores [28] and another that found that the elderly with healthier lifestyles believed themselves to be healthier than those with less healthy lifestyles [29]. The participants in this study showed high incidence of unhealthy lifestyles; a little over one-fifth of them (20.39\%) smoked. Interestingly, most of the smokers and drinkers were male and in good physical health. This could help to explain why smoking and drinking was associated with positive SRH. The possibility exists that the outcome resulted from the populations' desire to believe that they were healthy despite their smoking and drinking habits. Furthermore, there could also be a cultural explanation for the association between smoking and drinking and good health. Both activities typically serve as a means to socialize. However, this does not in any way contradict the extensive research that has confirmed the harm caused by smoking or excessive drinking.

\section{Conclusion}

Regional differences in SRH exist among the rural Chinese. Other factors also contribute to differences in SRH. After controlling for region, higher levels of household income, higher levels of education and good sources of social support improved SRH scores; being elderly, the presence of chronic illnesses, clinic visits and prior hospitalizations negatively impacted the scores.

Policy-makers should consider the benefits of programs when addressing health outcomes in financially distressed districts. Providing greater opportunities for economic development, strengthening social capital, increasing access to higher education and promoting to the availability of basic healthcare services could all serve to improve health outcomes, especially among the elderly and residents of low-income regions. Future research could further explore the positive impact of smoking and drinking on SRH.

\section{Limitations}

This was cross-sectional study, no cause-effect relationship between each social factors and SRH could be determined.

\section{Abbreviations}

NRCMs: New rural cooperative medical insurance; SRH: Self-rated health; SSRS: Social support rating scale

Acknowledgments

Not applicable. 


\section{Funding}

The research was supported in part by the National Natural Science Foundation for Youth of China (Reference: 71403004), funds for Ph.D. graduates from Anhui Medical University of China (PI: LW), and the Lupina Foundation, Canada (PI: WD).

\section{Availability of data and materials}

Please contact author for data requests.

\section{Authors' contributions}

LW wrote the manuscript and participated in questionnaire design. WD and QJ contributed to design of the study and the questionnaire. WD assisted with the revision of the manuscript. YO assisted with data analysis. SC, JC and $\mathrm{YO}$ participated in data collection. All authors read and approved the final manuscript.

\section{Ethics approval and consent to participate}

The study design and implementation were approved by the Anhui Medical University Research Ethics Committee.

\section{Consent for publication}

Not applicable.

\section{Competing interests}

The authors declare that they have no competing interests.

\section{Publisher's Note}

Springer Nature remains neutral with regard to jurisdictional claims in published maps and institutional affiliations.

\section{Author details}

${ }^{1}$ School of Health Management, Anhui Medical University, No.81, Mei Shan Road, Hefei 230032, Anhui, China. ${ }^{2}$ Anhui No.2 Provincial People's Hospital, NO.1868, Dangshan Road, Hefei 230041, Anhui, China. ${ }^{3}$ Department of Sociology and Legal Studies, University of Waterloo, 200 University Avenue West, Waterloo, ON N2L 3G1, Canada. ${ }^{4}$ Anhui Provincial Cancer Hospital, No. 107, Lake Road, Hefei 230031, Anhui, China. ${ }^{5}$ Children's Hospital of Nanjing Medical University, No.72,Guang Zhou Road, Nanjing 210008, Jiangsu, China ${ }^{6}$ School of Public Health, Anhui Medical University, No.81, Mei Shan Road, Hefei 230032, Anhui, China.

Received: 17 April 2018 Accepted: 18 October 2018

Published online: 08 November 2018

\section{References}

1. Dubikaytis T, Härkänen T, Regushevskaya E, Hemminki E, Haavio-Mannila E, Laanpere M, Kuznetsova O, Koskinen S. Socioeconomic differences in selfrated health among women: a comparison of St. Petersburg to Estonia and Finland. Int J Equity Health. 2014;13:39.

2. Svedberg P, Bardage C, Sandin S, Pedersen LN. A prospective study of health, life-style and psychosocial predictors of self-rated health. Eur J Epidemiol. 2006:21(10):767-76.

3. Miilunpalo S, Vuori I, Oja P, Pasanen M, Urponen H. Self-rated health status as a health measure: the predictive value of self-reported health status on the use of physician services and on mortality in the working-age population. J Clin Epidemiol. 1997;50(5):517-28.

4. Word Health Organization WHO. Health interview surveys: Towards international harmonization. Copenhagen: WHO Regional Office for Europe; 1996.

5. Page RM, Suwanteerangkul J. Self-rated health, psychosocial functioning, and health-related behavior among Thai adolescents. Pediatr Int. 2009:51(1):120-5.

6. Mossey JM, Shapiro E. Self-rated health: a predictor of mortality among the elderly. Am J Public Health. 1982;72(8):800-8.

7. Kaplan G, Barell V, Lusky A. Subjective state of health and survival in elderly adults. J Gerontol. 1988;43(4):S114-20.

8. Kondo N, Sembajwe G, Kawachi I, van Dam RM, Subramanian SV, Yamagata Z. Income inequality, mortality, and self rated health: meta-analysis of multilevel studies, BMJ. 2009:339:b4471.

9. Spurling G, Hayman N. Self-rated health status in an urban indigenous primary care setting: implications for clinicians and public health policy. Aust N Z J Public Health. 2010;34(6):598-601.
10. Malinauskiene V, Leisyte P, Romualdas M, Kirtiklyte K. Associations between self-rated health and psychosocial conditions, lifestyle factors and health resources among hospital nurses in Lithuania. J Adv Nurs. 2011;67(11):2383-93.

11. Millan-Calenti JC, Sanchez A, Lorenzo T, Maseda A. Depressive symptoms and other factors associated with poor self-rated health in the elderly: gender differences. Geriatr Gerontol Int. 2012;12(2):198-206.

12. Amstadter AB, McCauley JL, Ruggiero KJ, Resnick HS, Kilpatrick DG. Selfrated health in relation to rape and mental health disorders in a national sample of women. Am J Orthopsychiatry. 2011;81(2):202-10.

13. Yoo JP, Yoo MS. Impact of childhood socioeconomic position on self-rated health trajectories of south Korean adults. Asian Soc Work Policy Rev. 2016; 10(1):142-58.

14. Cramm JM, Nieboer AP. The influence of social capital and socio-economic conditions on self-rated health among residents of an economically and health-deprived south African township. Int J Equity Health. 2011;10:51.

15. Abdulrahim S, El AK. Is self-rated health a valid measure to use in social inequities and health research? Evidence from the PAPFAM women's data in six Arab countries. Int J Equity Health. 2012;11:53.

16. Bethea TN, Lopez RP, Cozier YC, White LF, McClean MD. The relationship between rural status, individual characteristics, and self-rated health in the behavioral risk factor surveillance system. J Rural Health. 2012;28(4):327-38

17. Chen $Y$, While $A E_{1}$ Hicks $A$. Self-rated health and associated factors among older people living alone in Shanghai. Geriatr Gerontol Int. 2015;15(4):457-64

18. Province NBoSoA: Anhui Statistical Yearbook. 2016.

19. Demirchyan A, Petrosyan V, Thompson ME. Gender differences in predictors of self-rated health in Armenia: a population-based study of an economy in transition. Int J Equity Health. 2012;11:67.

20. Xu J, Zhang J, Feng L, Qiu J. Self-rated health of population in southern China: association with socio-demographic characteristics measured with multipleitem self-rated health measurement scale. BMC Public Health. 2010;10:393.

21. Wu S, Wang R, Zhao Y, Ma X, Wu M, Yan X, He J. The relationship between self-rated health and objective health status. BMC Public Health. 2013;13:320.

22. Cai J, Coyte PC, Zhao H. Decomposing the causes of socioeconomic-related health inequality among urban and rural populations in China: a new decomposition approach. Int J Equity Health. 2017;16(1):128.

23. Satcher D. Include a social determinants of health approach to reduce health inequities. Public Health Rep. 2010;125(4):6-7.

24. Dong W, Wan J, Xu Y, Chen C, Bai G, Fang L, Sun A, Yang Y, Wang Y. Determinants of self-rated health among shanghai elders: a cross-sectional study. BMC Public Health. 2017;17(1):807.

25. Badawi G, Gariepy G, Page V, Schmitz N. Indicators of self-rated health in the Canadian population with diabetes. Diabet Med. 2012;29(8):1021-8.

26. Imai K, Gregg EW, Chen YJ, Zhang P, de Rekeneire N, Williamson DF. The association of BMI with functional status and self-rated health in US adults. Obesity. 2008;16(2):402-8.

27. Kashiwagi S. Relation between smoking habits and self-rated health of older persons in the Philippines: evidence-based tobacco policy advocacy. Open J Polit Sci. 2017:07(04):488-500.

28. Wang MP, Ho SY, Lo WS, Lai MK, Lam TH. Smoking is associated with poor self-rated health among adolescents in Hong Kong. Nicotine Tob Res. 2012; 14(6):682-7.

29. Lyu J, Lee SH, Kim HY. Associations between healthy lifestyles and health outcomes among older Koreans. Geriatr Gerontol Int. 2016;16(6):663-9.

Ready to submit your research? Choose BMC and benefit from

- fast, convenient online submission

- thorough peer review by experienced researchers in your field

- rapid publication on acceptance

- support for research data, including large and complex data types

- gold Open Access which fosters wider collaboration and increased citations

- maximum visibility for your research: over $100 \mathrm{M}$ website views per year

At BMC, research is always in progress.

Learn more biomedcentral.com/submissions 